\title{
New leadership for a user-friendly IPCC
}

\author{
Arthur Petersen, Jason Blackstock and Neil Morisetti
}

\section{The IPCC's new leadership needs to promote reforms to make the panel more relevant to the actors that use the organization's information.}

The information needs of decision-makers and practitioners around the world are varied and increasingly urgent. Yet, as these needs have expanded, there has been a widening gap between what most IPCC authors understand to be useful information and what decision-makers see as informative ${ }^{1-4}$.

IPCC reports command global respect and aid international climate negotiations. They have driven political consensus about the reality and risks of climate change over the past quarter century. But the focus of the climate conversation is rapidly changing. Most decisions on climate mitigation and adaptation are now widely distributed, with actors wrangling localized social, economic, business, ecological and political concerns.

While the "generic, untailored and untargeted"4 climate knowledge historically communicated by the IPCC has been effective for international political dialogue, it is not fit for the purpose of supporting distributed climate action in the coming decades. Despite the IPCC's influence on climate change knowledge, discourse about climate change, and climate policy development, there are significant obstacles to the use of this knowledge by those that urgently need to make decisions 5 .

While the IPCC is not (and will never be) able to satisfy all information needs, there are ways to enhance the relevance of its process, and enable scientifically credible actors to deliver user-focused scientific assessments on climate change. Here, we outline a number of ways the new IPCC leadership, elected in October 2015, can help the organization become more relevant.

\section{Reforms}

The Task Group on the Future Work of the IPCC was established at a plenary session in Batumi, Georgia, in October 20136. Participants in an independent workshop on reforms, held in February 2014 at University College London, came from IPCC member governments, the Executive Committee, intergovernmental organizations, national government departments, city governments, business and non-governmental organizations ${ }^{7}$. The outcomes of that workshop were presented at the first meeting of the task group in Berlin in April 2014.

Here we summarize the main recommendations for a possible evolution of the IPCC, which have as of yet only partly been taken up in the Decision on Future Work of the IPCC of February 2015:

Good practice. There is a need to improve the way IPCC data and findings are used by actors at national and subnational levels. The IPCC could extend its methodological work for this purpose. In particular, it could partner with academic institutions to provide training in climate [910] assessment (using 
manuals and a system of accreditation) aimed at talented academics from developing countries, enabling a new cadre of scientists to generate more userfocused information.

While the Decision on Future Work states that the IPCC "will consider to develop other methodology reports or good practice guidance reports, for example, to facilitate preparation of regional and/or national scientific assessments" 8 , how the findings can best be translated to other venues is not addressed. Furthermore, while reference is made to the training of Technical Support Units (TSUs) and author teams, there is no reference to training prospective authors from developing countries.

Frequency. In a world where momentum is building towards a low-carbon clean-tech society, ever more actors are asking questions on what needs to be done, how and where. Given the scale of capital and human talent investment, there is an increasing need for continuous assessment and monitoring of this 'solution space'. The IPCC could fill a substantial component of this knowledge gap by increasing the frequency of its activities.

The Decision on Future Work maintains a focus on producing comprehensive assessment reports every 5 to 7 years, with working group reports staggered 1 to 1.5 years after each other, and no reference is made to an increased frequency of outputs. This timeline is out of sync with the rapidly evolving informational needs of climate actors.

Reporting mechanism. An alternative model to deliver expert assessments on climate change, which departs from the static content offered by the IPCC, would be a web-based dynamic model in which frequent updates are made if the scientific community feels that a change needs to be made ${ }^{9}$. This model could facilitate a high level of transparency by allowing users to get to the sources of statements and data more easily. Tailored portals could also be added that cater to specific user groups.

There are issues around filtering and review in this model, so the Decision on Future Work does not go further than requesting "the IPCC Secretariat to facilitate and enhance further the consistent and coherent use of up to date digital technology for sharing and disseminating information"8.

Synthesis Report. In order to make the working groups speak to each other in a way that could lead to an informative synthesis, the IPCC could structure its comprehensive assessment cycle, which includes the production of three working group reports, around what is needed for the Synthesis Report.

The Decision on Future Work did not make the structuring role of the Synthesis Report explicit. But a necessary - though not sufficient - condition was at least fulfilled: the scoping of the Synthesis Report "should start at an early stage" 8 .

Special Reports. The IPCC could consider the production of a number of Special Reports in collaboration with other organizations. This could increase the frequency of relevant IPCC outputs and engage user communities in the coproduction of assessments, perhaps improving their reception. 
The Decision on Future Work only says that "the identification of Special Reports, including those with a focus on regional information and priorities, should be made as early as possible and in the context of all deliverables of the

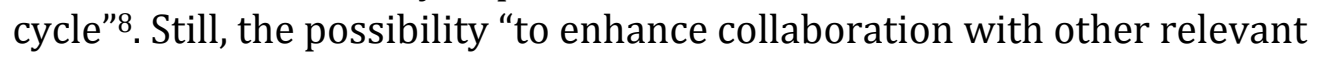
international and scientific organizations" 8 was explicitly left open.

Sharing resources. One way to enhance developing country participation in the IPCC is to ensure that all TSUs are shared between developed and developing country Working Group/Task Force Co-Chairs. This would partially address the present imbalance in the involvement of developing countries in the production of the IPCC reports.

The Decision on Future Work includes the option of joint hosting of TSUs, and if the TSU is not jointly hosted then the other Co-Chair will be assisted to have "a strong link to, and coordination with" 8 that TSU.

\section{New leadership}

Although some steps have been taken to make it possible for the IPCC to become more relevant, we believe that the Decision on Future Work should have gone further. The world does not need yet more comprehensive assessments, and we argue that the IPCC should focus instead on finding a useful role in an ecosystem of institutions, focusing on the real needs of actors.

All is not lost. The new leadership of the IPCC (Chair, Vice-Chairs, Working Group and Task Force Co-Chairs and other Bureau Members), elected in October 2015, has the potential to move forward on all six fronts.

Nothing prevents the IPCC from engaging with partners to train potential authors, particularly from developing countries, in performing scientific assessments. A formal accreditation system could also be established in connection with such training, for instance, via the International Council for Science. These activities should then be aimed at talented academics from developing countries and [911] could facilitate translating IPCC findings to other venues.

While no explicit reference is made to an increased frequency of outputs, the new leadership could cover emerging and fast-moving areas of science and relevant themes in adaptation and mitigation in the interim using "short, targeted reports" 10 or "topical assessment papers"11, which can be woven into comprehensive reports.

The production of such short, targeted reports or topical assessments could address the need for flexible updates of the present, fifth, assessment report. Such changes could be combined with an effort coordinated by the Secretariat on the deployment of digital technology to facilitate easier access to data.

We argue that the new leadership treats these three recommendations as the highest priority. Furthermore, the new Chair of the IPCC, who is mainly responsible for the Synthesis Report, could work with the new Working Group Co-Chairs to ensure the Synthesis Report works as a collaborative structuring device for the assessment as a whole. This requires an appropriate, staggered, scoping design for the assessment as a whole, which should start with the Synthesis Report. 
Since there is no prohibition on working with partners in the production of special reports, governments could be asked to come up with report proposals to be co-produced with partners. Formal partnership with private sector networks may raise eyebrows, but for sectors such as energy and reinsurance, the collective and corporate interests of having these industries effectively informed and prepared to ameliorate climate risks emphasizes the need to find a politically workable solution.

Finally, in order to significantly increase the size and quality of the national research base vis-à-vis climate change in developing countries, the IPCC leadership could encourage international and national actors to set up collaborations between institutions in developed and developing countries. It is crucial for the IPCC that the group of experts available for participation in the IPCC becomes more representative.

Adopting such an approach will ensure the IPCC remains a relevant force in addressing one of the greatest challenges of the twenty-first century.

Arthur Petersen, Jason Blackstock and Neil Morisetti are in the Department of Science, Technology, Engineering and Public Policy (STEaPP), University College London, Gower Street, London WC1E 6BT, UK. e-mail: arthur.petersen@ucl.ac.uk

\section{References}

1. Lemos, M.C., Kirchhoff, C.J. \& Ramprasad, V. Nature Clim. Change 2, 789-794 (2012).

2. Beck, S. et al. Gaia 23,80-87 (2014).

3. Viner, D. \& Howarth, C. Nature Clim. Change 4, 848-850 (2014).

4. Howarth, C. \& Black, R. Nature Clim. Change 5, 506-508 (2015).

5. Hulme, M. \& Mahony, M. Prog. Phys. Geog. 34, 705-718 (2010).

6. IPCC Decision Taken with Respect to the Task Group on the Future Work of the IPCC: Terms of Reference. 37th Session of the IPCC, 14-18 October 2013, Batumi, Georgia (IPCC, 2013); http://www.ipcc.ch/meetings/session37/p37_decision_future.pdf

7. Petersen, A.C., Morisetti, N. \& Blackstock, J. B. Partnering with the Users of IPCC Products: How Best to Deliver Scientific Assessments on Climate Change. Report of a Workshop held at UCL on 4 and 5 February 2014 (UCL STEaPP, 2014); http://www.ucl.ac.uk/steapp/research/projects/ipcc

8. IPCC Decisions Adopted by the Panel. 41st Session of the IPCC, 24-27 February 2015, Nairobi, Kenya (IPCC, 2015); http://www.ipcc.ch/meetings/session41/p41_decisions.pdf

9. Hulme, M., Zorita, E., Stocker, T.F., Price, J. \& Christy, J.R. Nature 463, 730-732 (2010).

10. Griggs, D. Nature 508, 171-173 (2014).

11. Stocker, T.F. \& Plattner, G-K. Nature 513, 163-165 (2014). 